clefts; craniofacial surgery and facial aesthetics. They are all very informative and give you a step by step approach to various surgical procedures as well as their potential complications.

Following each chapter there are tables containing top tips that summarise the information and further reading titles to allow one to expand their knowledge in relevant areas. This book is excellent in terms of detail and has outstanding illustrations which really enhance your learning experience. Thoroughly recommended for all past, present and future maxillofacial trainees.

P. Acharya

\section{COHEN'S PATHWAYS OF THE PULP, 10TH EDITION}

\begin{tabular}{ll}
\hline K. Hargreaves, S. Cohen \\
UK: Elsevier \\
Pathways of the \\
PULPe £96.99; pp 992 \\
ISBN 9780323064897
\end{tabular}

This is a comprehensive reference text for all things endodontics. The first edition was published in 1976 and it is now on its tenth edition.

Initially the book discusses the science of endodontics by covering topics such as diagnosis, instruments, materials, the structure of the dentine-pulp complex, pathobiology and microbiology. It then progresses to discuss all aspects of clinical endodontics. The tenth edition includes five new chapters, three in print and two online, including: Pathobiology of the Periapex, Regenerative Endodontics, Restoration of Endodontically Treated Teeth, Cone Beam Imaging for Endodontics and Key Principles of Endodontic Practice Management.

Previous editions have been criticised in reviews for being too wordy and having an overwhelming amount of in depth scientific background. I can sympathise with this view and at times the text was pretty heavy going. However, I felt that the detail complemented the relevant clinical topics and did in fact enhance the reader's understanding.

The book is well illustrated and I will definitely refer back to some of the images on 'instrumentation of the root canal' and also a series of 'summary boxes' which detail the preferred access cavity, average numbers and lengths of canals for each tooth.

I was impressed by the online content which included the whole text as well as five additional 'online only' chapters, a library of images, videos, case studies and quizzes. I found the search function online to be particularly handy as small text inserts were part of the search results which allowed you to quickly judge what was relevant to your particular query.

One of the nicest, and I think most important, online features is the 'updates' area. Textbooks are often criticised for being out of date at publication but this feature allows the text to be kept in line with recent developments. This is demonstrated by the discussion of self-adjusting files (SAF), a novel technique using hollow files oscillating in an up-and-down fashion with irrigation being pumped through the file. This technique is covered in the book but updates have been added online, in the relevant section of the text, as and when research was published.

In conclusion this is a comprehensive and well illustrated reference book which would be of use to both students and practitioners, particularly those with an interest in endodontics.

\section{R. Holliday}

\section{MANAGING A DENTAL PRACTICE THE GENGHIS KHAN WAY}

\begin{tabular}{|c|c|}
\hline 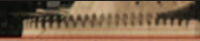 & M. R. Young \\
\hline 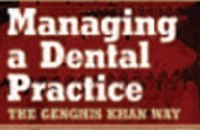 & $\begin{array}{l}\text { UK: Radcliffe } \\
\text { price £27.99; pp } 148 \\
\text { ISBN } 9781846193965\end{array}$ \\
\hline ithingents & \\
\hline
\end{tabular}

Written from the pen of experience, this book seeks to provide a clear and logical framework for those wishing to establish an effective and efficient management model in dental practice.

It draws into sharp focus the fundamental strategies of practice leadership, whilst acknowledging the key aims of delivering optimal patient care and operating a successful business.

The book is written in a conversational style, accessible, engaging and infused with wit. The content is practical and informative. The tone is both inspirational and cautionary. Throughout, the text is peppered with personal anecdotes from the author, relatable examples of management triumphs and failures. In spite of the author's extensive experience in the fields of management and marketing, the book is refreshingly free of mysterious industry jargon.

The structure is exceptionally userfriendly. The main body of the book is subdivided into four sections: Preparation, People, Planning, and Policies and Procedures. The facets of each domain are explored under clear sub-headings, in a logical progression. The frequent expression of information using bullet points enables concepts to be absorbed and revisited easily. Key ideas are illustrated in simple diagrammatical format.

'Preparation' defines the process of management. It extols the benefits of rational long-term planning prior to assuming a management role. It encourages the reader to consider the involvement of the entire dental team and those in professions auxiliary to business, in the running of a practice.

'People' examines the importance of a glowing and ethical practice ethos, the provision of patient-centred services. The importance of the composition of the dental team, recognition of individuals' strengths and skills, and the value of investing in employee development are explored.

'Planning' offers practical advice and tools to help foster an objective-focussed and cohesive operation. The concept of 'strategy' in the context of business planning, financial forecasting and marketing is extrapolated in full.

'Policies and Procedures' highlights legal requirements and prudent measures to take concerning documentation.

This book is relevant to those in NHS, private and specialist sectors; small and large practices alike. It would be of direct value to those involved in practice management at any level and in any capacity. For those considering adopting a management related role, it would serve as an ideal first read with concise yet comprehensive coverage of the topic.

R. Emmott 